\title{
Coxa Profunda
}

\section{Is the Deep Acetabulum Overcovered?}

\author{
Lucas A. Anderson MD, Ashley L. Kapron BS, \\ Stephen K. Aoki MD, Christopher L. Peters MD
}

Published online: 17 August 2012

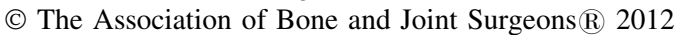

\begin{abstract}
Background Coxa profunda, or a deep acetabular socket, is often used to diagnose pincer femoroacetabular impingement (FAI). Radiographically, coxa profunda is the finding of an acetabular fossa medial to the ilioischial line. However, the relative position of the acetabular fossa to the pelvis may not be indicative of acetabular coverage.

Questions/purposes We therefore determined the incidence of coxa profunda and evaluated associations between coxa profunda and other radiographic parameters of acetabular coverage commonly used to diagnose pincer FAI and acetabular dysplasia.
\end{abstract}

\footnotetext{
The institution or one or more of the authors (LAA, ALK, SKA, CLP) has received, during the study period, funding from Biomet Inc (Warsaw, IN, USA), ArthroCare (Austin, TX, USA), Smith \& Nephew Inc (Memphis, TN, USA), and the NIH (R01AR053344-02). One of the authors (SKA) certifies that he has received or may receive payments or benefits, during the study period, an amount of less than $\$ 10,000$ from Smith \& Nephew and ArthroCare. One of the authors (CLP) certifies that he has received or may receive payments or benefits, during the study period, an amount in excess of $\$ 100,001$ to $\$ 1,000,000$ from Biomet Inc.

All ICMJE Conflict of Interest Forms for authors and Clinical Orthopaedics and Related Research editors and board members are on file with the publication and can be viewed on request.

Each author certifies that his or her institution approved the human protocol for this investigation, and that all investigations were conducted in conformity with ethical principles of research, and that informed consent for participation in the study was obtained.
}

L. A. Anderson, A. L. Kapron, S. K. Aoki, C. L. Peters ( $\square)$ Department of Orthopaedics, University of Utah, 590 Wakara Way, Salt Lake City, UT 84108, USA

e-mail: Christopher.Peters@ @sc.utah.edu

\section{A. L. Kapron}

Department of Biomechanics, University

of Utah, Salt Lake City, UT, USA
Methods We evaluated the radiographs of three cohorts for coxa profunda, lateral center edge (LCE) angle, acetabular index, posterior wall sign, and crossover sign. Data from 67 collegiate football players were collected prospectively (Cohort 1). We identified two patient cohorts through retrospective review of all 179 hips undergoing hip preservation surgery from 2002 to 2008 (83 periacetabular osteotomies [Cohort 2] and 96 surgical dislocation and osteochondroplasties [Cohort 3]).

Results In all three cohorts, we detected no difference in the LCE angle or acetabular index between hips with and without coxa profunda. Coxa profunda existed in hips representing the spectrum of acetabular coverage measured by LCE angle $\left(-18^{\circ}\right.$ to $\left.60^{\circ}\right)$ and acetabular orientation determined by the crossover sign.

Conclusions Coxa profunda was a common radiographic finding in both symptomatic patients and asymptomatic football players. Coxa profunda existed in hips representing the spectrum of acetabular coverage and was not associated with an overcovered acetabulum. We conclude coxa profunda is unrelated to overcoverage and suggest its use in diagnosis of pincer FAI be abandoned in favor of other determinants of focal or general overcoverage.

Level of Evidence Level III, diagnostic study. See Instructions for Authors for a complete description of levels of evidence.

\section{Introduction}

Our understanding of femoroacetabular impingement (FAI) as a cause of hip pain in the young adult has progressed greatly in recent years. FAI results from abnormal hip morphology and presents as femoral sided (cam), acetabular sided (pincer), or a combination [3]. Cam impingement is 
caused by an aspherical head or decreased head-neck offset believed to increase internal shear stress within the acetabulum as the hip is flexed and internally rotated. Pincer impingement is believed to result from abnormal extension of the anterior and/or posterior walls or acetabular roof relative to the center of the femoral head, causing an abutment of the acetabular rim against the femoral head-neck junction [10]. Criteria to describe morphologic abnormalities such as acetabular retroversion and coxa profunda, entities believed to produce so-called pincer impingement, have been proposed, and with increased clinical experience, questions about some of these criteria have arisen. For example, traditional thought equates coxa profunda, defined by the acetabular fossa touching or crossing the ilioischial line, with acetabular overcoverage and, as a result, has classified hips with this radiographic finding as having pincer FAI [3-7, 10, 16, 21-23, 27-30, 32, 34, 36, 38].

Some have even termed coxa profunda the "prototype of the deep hip" [3]. However, our clinical experience suggests this relationship may not always hold true. If coxa profunda is used as a criterion to diagnosis pincer FAI within hip preservation surgical algorithms, an inappropriate procedure may be selected (such as rim resection rather than acetabular reorientation).

We answered the following questions: (1) What is the incidence of radiographic coxa profunda defined by the acetabular fossa touching or medial to the ilioischial line in three cohorts with symptomatic and asymptomatic hips with differing morphologies: asymptomatic collegiate football players, patients undergoing periacetabular osteotomy (PAO) for acetabular undercoverage (dysplasia) or retroversion, and patients undergoing surgical dislocation for FAI? And what is the relationship between coxa profunda and other radiographic measures of (2) acetabular coverage (lateral center edge [LCE] angle and acetabular index) and (3) acetabular retroversion (crossover sign and posterior wall sign) commonly used to diagnose pincer FAI and acetabular dysplasia?

\section{Patients and Methods}

We examined radiographs from three cohorts (Table 1). Cohort 1 included radiographs of 67 asymptomatic male football players obtained as part of a prospective, institutional review board-approved study to determine the incidence of radiographic findings of FAI in collegiate football players [15]. Each subject completed a short questionnaire on the same day the radiographs were taken. This questionnaire was based on the validated Hip Outcome Score and was designed to ascertain the condition of the hip during the previous week $[18,19]$. To create Cohorts 2 and 3, we retrospectively reviewed the radiographs of all 175 patients (179 hips) who had open hip preservation surgery from 2002 to 2008. These patients selected by review of our prospective surgical database and time period achieved comparable cohort sizes. From these 179 hips, we identified 83 hips in 81 patients (58 women) who had undergone PAO for acetabular undercoverage (dysplasia) or retroversion with a PAO technique described previously $[9,24]$ (Cohort 2) and 96 hips in 94 patients (40 women) who had undergone open surgical dislocation for FAI $[8,25]$ (Cohort 3). The indications for PAO were (1) hip pain and (2) radiographic evidence of either lateral undercoverage or substantial retroversion coupled with posterior wall deficiency. Indications for osteochondroplasty were (1) hip pain, (2) a positive impingement sign on physical examination, and (3) radiographic evidence of a cam deformity such as a decreased head-neck offset or an abnormal alpha angle $\left(>50^{\circ}\right)$. The contraindications for PAO were (1) age greater than 45 years and (2) radiographic evidence of substantial osteoarthritis (moderate to severe joint space narrowing, bone cysts, or a large chondral delamination on MRI in an area that would be weightbearing after rotation). The contraindication for osteochondroplasty was severe joint space narrowing. Supine pelvic AP radiographs were acquired with gonad shielding in Cohort 1 and standing AP radiographs without shielding in Cohorts 2 and 3. Radiographs were visually inspected for excessive tilt and rotation [26, 35]. Nine patients from Cohort 2 had inadequate radiographs and thus were excluded, leaving 74 hips (67 patients).

Three observers (LAA, SKA, LP), none being the treating surgeon, completed the radiographic reads. All reads were performed on both hips in Cohort 1 but only on the operative hips in Cohorts 2 and 3 (except for determining contralateral coxa profunda or protrusio). Coxa profunda was identified if the acetabular fossa was medial to or touching the ilioischial line [3] (Fig. 1). Protrusio acetabuli was also noted if the femoral head was touching or medial to the ilioischial line [3]. General acetabular coverage was evaluated with the LCE angle and acetabular index. The LCE angle was formed by a vertical line referenced off the pelvis and a line connecting the femoral head center with the lateral edge of the acetabular sourcil [34]. An LCE angle of greater than $40^{\circ}$ indicated overcoverage or pincer FAI [1] (Fig. 2), while an LCE angle of less than $25^{\circ}$ defined acetabular undercoverage or dysplasia [20] (Fig. 3). The acetabular index was the angle formed by a horizontal line referenced off the pelvis and a line connecting the medial point of the sclerotic zone with the lateral edge of the sourcil [34]. An acetabular index between $0^{\circ}$ and $10^{\circ}$ was considered normal, while an index of less than $0^{\circ}$ indicated pincer impingement and an index of greater than $10^{\circ}$ indicated acetabular dysplasia [5]. 
Table 1. Demographic and continuous radiographic parameters

\begin{tabular}{|c|c|c|c|c|c|c|c|c|c|}
\hline \multirow[t]{2}{*}{ Variable } & \multicolumn{3}{|c|}{ Cohort 1 (football players) } & \multicolumn{3}{|c|}{ Cohort 2 (PAO) } & \multicolumn{3}{|c|}{ Cohort 3 (SDO) } \\
\hline & Mean \pm SD & Range & $95 \% \mathrm{CI}$ & Mean \pm SD & Range & $95 \% \mathrm{CI}$ & Mean \pm SD & Range & $95 \% \mathrm{CI}$ \\
\hline Age (years) & $21 \pm 1.9$ & $17-26$ & $21-22$ & $29 \pm 8.7$ & $15-47$ & $27-31$ & $29 \pm 9.2$ & $14-51$ & $27-31$ \\
\hline Weight (kg) & $102 \pm 19$ & $75-144$ & $98-107$ & $73 \pm 17$ & $50-113$ & $68-77$ & $79 \pm 18$ & $44-120$ & $76-83$ \\
\hline Height (cm) & $185 \pm 6.3$ & $170-197$ & $183-186$ & $168 \pm 11$ & $140-191$ & $165-171$ & $174 \pm 9.5$ & $155-193$ & $172-176$ \\
\hline LCE angle $\left(^{\circ}\right)$ & $30 \pm 6.7$ & $14-45$ & $29-31$ & $7.1 \pm 11.8$ & -20 to 34 & $4.3-9.8$ & $33 \pm 12$ & $0-63$ & $31-36$ \\
\hline $\begin{array}{l}\text { Acetabular } \\
\text { index }\left({ }^{\circ}\right)\end{array}$ & $4.2 \pm 5.7$ & -9.0 to 19 & $3.2-5.2$ & $22 \pm 9.9$ & $2-48$ & $20-25$ & $6.7 \pm 7.7$ & -16 to 38 & $5.1-8.2$ \\
\hline
\end{tabular}

$\mathrm{PAO}=$ periacetabular osteotomy; $\mathrm{SDO}=$ surgical dislocation and osteochondroplasty; LCE = lateral center edge.

Fig. 1A-B Preoperative (A) cropped false-profile and (B) AP pelvis radiographs show the hip of a 28 -year-old man who underwent surgery for impingement. The AP pelvis radiograph demonstrates coxa profunda (acetabular fossa medial to or touching the ilioischial line) and normal LCE angle. Acetabular retroversion is present, reflected by a positive crossover sign (anterior wall crossing lateral to the posterior wall superiorly), and posterior acetabular deficiency, demonstrated by a positive posterior wall sign (posterior acetabular rim medial to the center of the femoral head).
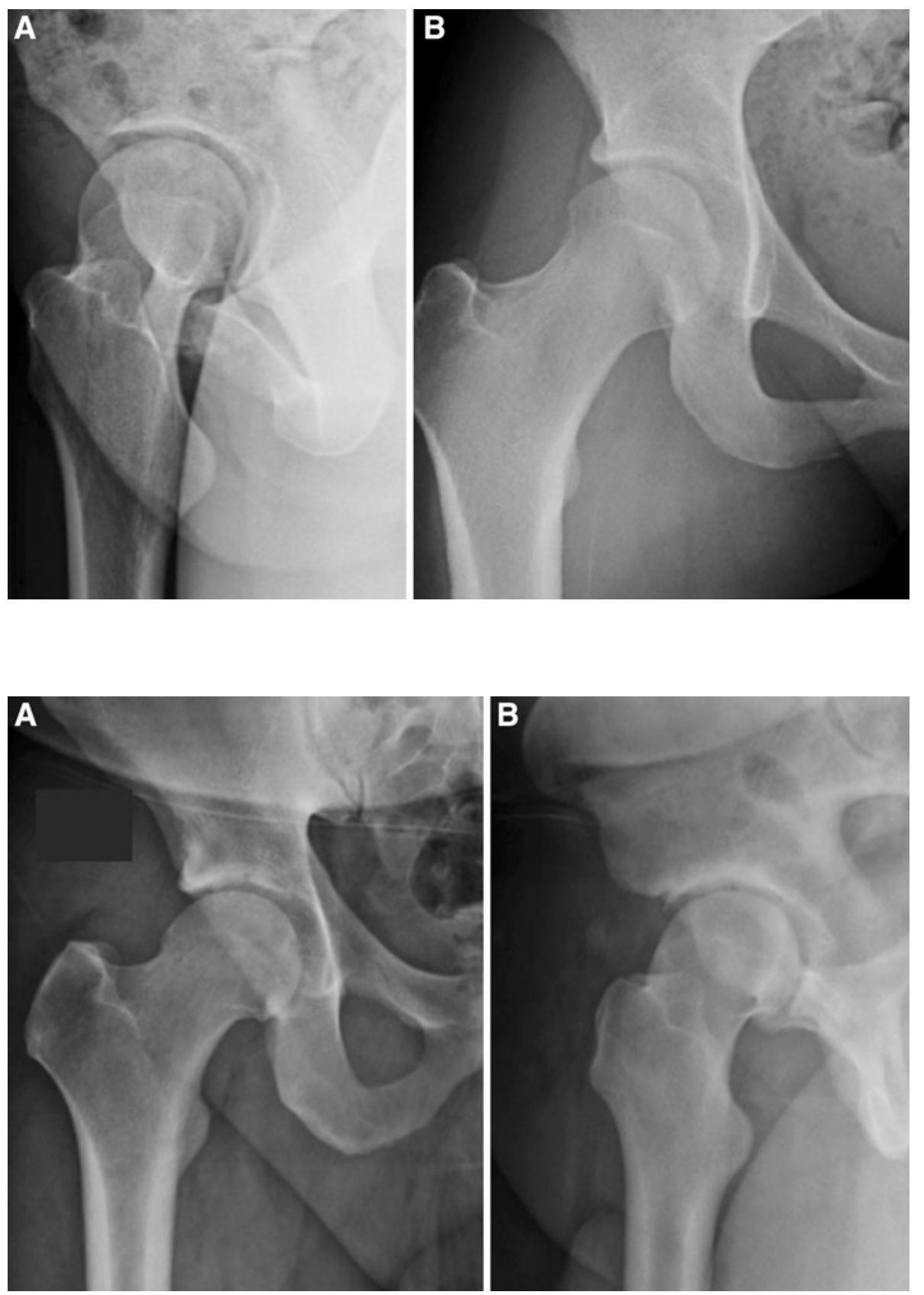

Fig. 2A-B Preoperative (A) cropped $\mathrm{AP}$ pelvis and (B) false-profile radiographs show the hip of a 36-year-old man who underwent surgery for impingement. The radiographs demonstrate coxa profunda and acetabular overcoverage (ACE and LCE angles $>40^{\circ}$ ). 
Fig. 3A-B Preoperative (A) false-profile and (B) cropped AP pelvis radiographs show the hip of a 23 -yearold woman who underwent PAO. The radiographs demonstrate coxa profunda and deficient acetabular coverage (ACE and LCE angles $<20^{\circ}$ ).
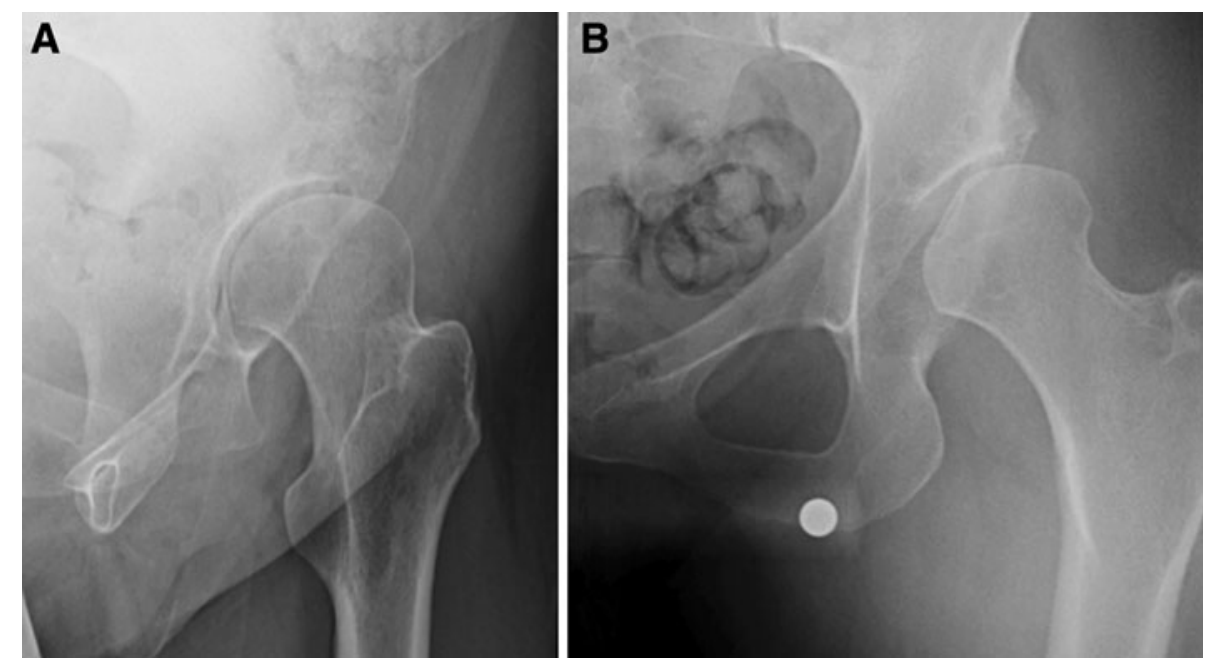

We evaluated acetabular retroversion and focal acetabular coverage using two qualitative measurements: the crossover and posterior wall signs. The crossover sign was positive when the posterior wall of the acetabulum crossed the anterior wall, signifying acetabular retroversion, relative anterior overcoverage, or posterior undercoverage [31, 37] (Fig. 1). The posterior wall sign was positive when the posterior wall was medial to the center of femoral head, indicating posterior acetabular deficiency [11, 37] (Fig. 3).

Inter- and intraobserver repeatability was moderate or better for all radiographic measurements, as reported in a prior study of Cohort 1 [15]. The respective kappa values for inter- and intraobserver reads were 0.82 and 0.82 for coxa profunda, 0.59 and 0.68 for the crossover sign, and 0.71 and 0.85 for the posterior wall sign. The respective intraclass correlation coefficients for inter- and intraobserver reads were 0.76 and 0.80 for acetabular index and 0.85 and 0.85 for LCE angle.

We determined differences in the continuous radiographic data (LCE angle, acetabular index) and differences in the presence of the crossover sign and posterior wall sign between hips with and without profunda using randomeffects linear regression models. Random-effects models were utilized to account for dependent observations (left and right hips), which were included for all subjects in Cohort 1 and for those patients in Cohorts 2 and 3 who underwent bilateral procedures.

\section{Results}

In Cohort 1, 45 of 134 (34\%) hips had coxa profunda. When coxa profunda was present in an individual in Cohort 1 , it occurred bilaterally $81 \%$ of the time. According to the self-reported Hip Outcome Score questionnaire, the majority (62 of 67) of the players were asymptomatic (both activities of daily living and sports subscores $>90 \%$ ). One player had an activities of daily living subscore of $72 \%$ and a sports subscore of $78 \%$. This subject had bilateral coxa profunda and crossover signs and the lowest femoral headneck offset of the cohort [15]. Four additional players had a sports subscore of between $80 \%$ and $90 \%$, one of which had coxa profunda of the right hip. In the symptomatic patient cohorts, 43 of $74(58 \%)$ operative hips in Cohort 2 and 54 of $96(56 \%)$ operative hips in Cohort 3 had coxa profunda (Table 2). In Cohort 2, when the operative hip had profunda, it was also present in 39 of $43(93 \%)$ of contralateral hips. In Cohort 3, when the operative hip had coxa profunda, it was also present in 53 of 56 (95\%) of contralateral hips. We found only one hip (in Cohort 3) with protrusio acetabuli in this study.

Within each cohort, there were no differences in LCE angle or acetabular index between hips with and without coxa profunda (Table 3). Furthermore, coxa profunda coexisted with a spectrum of acetabular morphologies and orientations (Table 2). In Cohort 1, only four of $45(9 \%)$ hips with coxa profunda met the lateral coverage criteria for overcoverage or pincer impingement (Fig. 4). Thirtysix of $45(80 \%)$ hips with coxa profunda had normal coverage and five of $45(11 \%)$ hips met the criteria for deficient coverage. In Cohort 2, the majority of the hips with coxa profunda had deficient coverage (38 of 43 hips, $88 \%$ ) while none had overcoverage (Fig. 5). In Cohort 3, 13 of 54 (24\%) hips had overcoverage, 28 of 54 (52\%) hips had normal coverage, and 13 of 54 (24\%) hips with coxa profunda were associated with deficient coverage (Fig. 6).

Coxa profunda did not consistently coexist with the crossover sign and posterior wall sign in the three cohorts (Table 2). In Cohort 1, hips with coxa profunda had a 
Table 2. Radiographic findings

\begin{tabular}{|c|c|c|c|c|c|c|}
\hline \multirow{3}{*}{$\begin{array}{l}\text { Sign of pincer } \\
\text { impingement }\end{array}$} & \multicolumn{6}{|c|}{ Percentage of hips } \\
\hline & \multicolumn{2}{|c|}{ Cohort 1 (football players) } & \multicolumn{2}{|c|}{ Cohort 2 (PAO) } & \multicolumn{2}{|c|}{ Cohort 3 (SDO) } \\
\hline & $\begin{array}{l}\text { All hips } \\
(\mathrm{n}=134)\end{array}$ & $\begin{array}{l}\text { Profunda hips } \\
(\mathrm{n}=45)\end{array}$ & $\begin{array}{l}\text { All hips } \\
(\mathrm{n}=74)\end{array}$ & $\begin{array}{l}\text { Profunda hips } \\
(\mathrm{n}=43)\end{array}$ & $\begin{array}{l}\text { All hips } \\
(\mathrm{n}=96)\end{array}$ & $\begin{array}{l}\text { Profunda hips } \\
(\mathrm{n}=54)\end{array}$ \\
\hline Coxa profunda & 34 & & 58 & & 56 & \\
\hline Crossover sign & 69 & 73 & 28 & 23 & 30 & 20 \\
\hline Posterior wall sign & 72 & 51 & 82 & 77 & 43 & 43 \\
\hline \multicolumn{7}{|l|}{ Acetabular index } \\
\hline$<0^{\circ}$ & 14 & 18 & 0 & 0 & 8 & 5 \\
\hline $0^{\circ}-10^{\circ}$ & 70 & 78 & 14 & 16 & 66 & 65 \\
\hline$>10^{\circ}$ & 16 & 4 & 86 & 84 & 26 & 30 \\
\hline \multicolumn{7}{|l|}{ LCE angle } \\
\hline$<25^{\circ}$ & 23 & 11 & 92 & 88 & 22 & 24 \\
\hline $25^{\circ}-40^{\circ}$ & 71 & 80 & 8 & 12 & 56 & 52 \\
\hline$>40^{\circ}$ & 6 & 9 & 0 & 0 & 22 & 24 \\
\hline
\end{tabular}

$\mathrm{PAO}=$ periacetabular osteotomy; $\mathrm{SDO}=$ surgical dislocation and osteotomy; LCE = lateral center edge.

Table 3. Continuous radiographic parameters in hips with and without coxa profunda

\begin{tabular}{|c|c|c|c|c|c|c|c|}
\hline \multirow[t]{2}{*}{ Subjects } & \multirow[t]{2}{*}{ Number of hips } & \multicolumn{3}{|c|}{ LCE angle $\left(^{\circ}\right)$} & \multicolumn{3}{|c|}{ Acetabular index $\left({ }^{\circ}\right)$} \\
\hline & & Mean \pm SD & Range & $\mathrm{p}$ value & Mean \pm SD & Range & $\mathrm{p}$ value \\
\hline \multicolumn{8}{|c|}{ Cohort 1 (football players) } \\
\hline Profunda & 45 & $32 \pm 6.0$ & $20-45$ & 0.100 & $2.6 \pm 4.8$ & -9.0 to 13 & 0.201 \\
\hline No profunda & 89 & $29 \pm 6.8$ & $14-43$ & & $5.0 \pm 6.0$ & -8.0 to 19 & \\
\hline \multicolumn{8}{|c|}{ Cohort 2 (PAO) } \\
\hline Profunda & 43 & $7.3 \pm 12$ & -20 to 34 & 0.930 & $21 \pm 9.4$ & $2-44$ & 0.126 \\
\hline No profunda & 31 & $6.7 \pm 11$ & -18 to 30 & & $25 \pm 10$ & $5-48$ & \\
\hline \multicolumn{8}{|l|}{ Cohort 3 (SDO) } \\
\hline Profunda & 54 & $34 \pm 11$ & $5-63$ & 0.586 & $7.4 \pm 6.4$ & -15 to 24 & 0.221 \\
\hline No profunda & 42 & $32 \pm 12$ & $0-53$ & & $5.7 \pm 9.1$ & -16 to 38 & \\
\hline
\end{tabular}

$\mathrm{PAO}=$ periacetabular osteotomy; $\mathrm{SDO}=$ surgical dislocation and osteochondroplasty; $\mathrm{LCE}=$ lateral center edge.

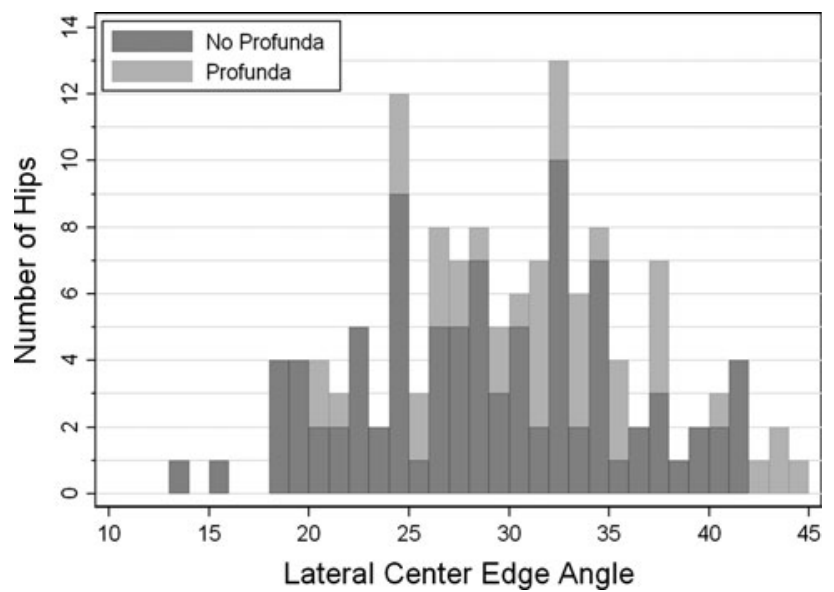

Fig. 4 A bar graph demonstrates the distribution of LCE angles in hips with and without coxa profunda in Cohort 1 (football players). Note the majority of the hips both with and without coxa profunda had normal coverage.

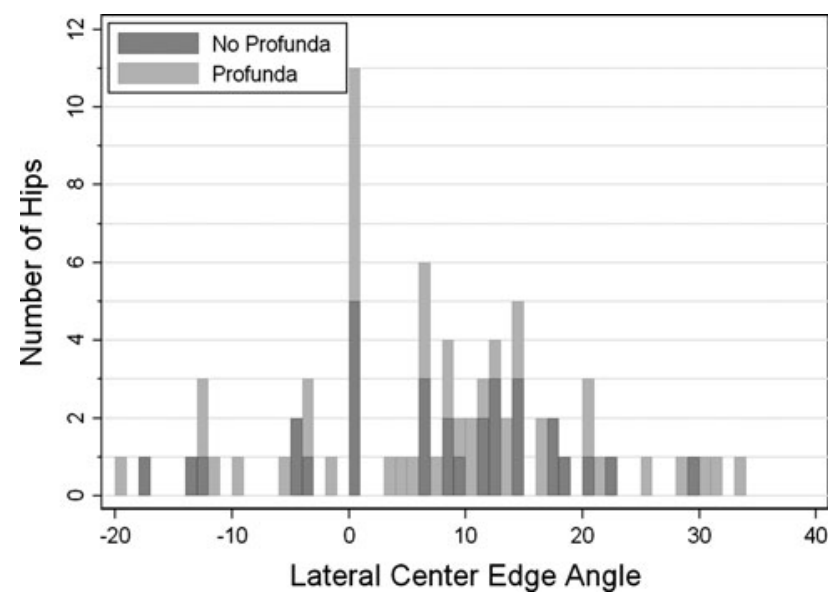

Fig. 5 A bar graph demonstrates the distribution of LCE angles in hips with and without profunda in Cohort 2 (patients with PAO). Note the majority of the hips both with and without coxa profunda had either normal or undercoverage. 


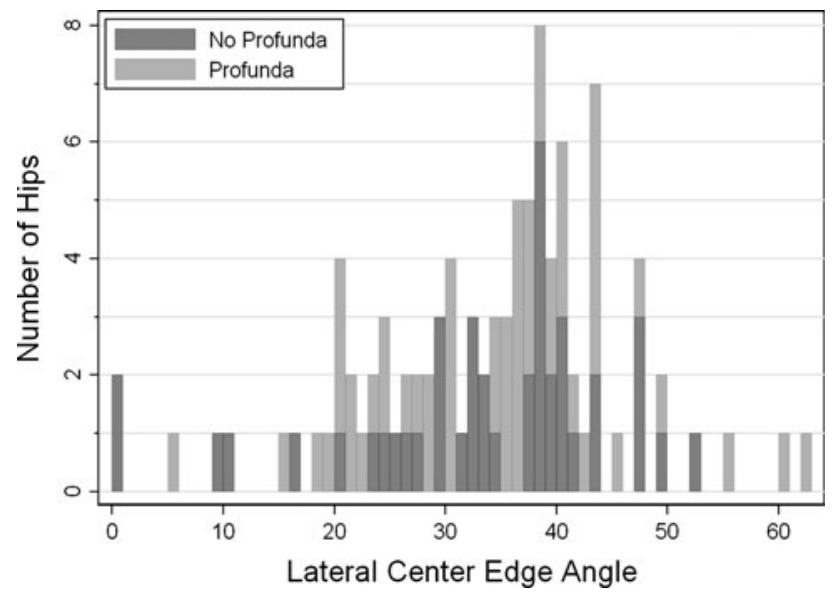

Fig. 6 A bar graph demonstrates the distribution of LCE angles in hips with and without profunda in Cohort 3 (patients with surgical dislocation). Note the majority of the hips both with and without coxa profunda had either normal or overcoverage.

lower $(\mathrm{p}=0.012)$ incidence of the posterior wall sign than those without coxa profunda. Additionally, in Cohort 3, hips with coxa profunda had a lower $(\mathrm{p}=0.012)$ incidence of the crossover sign. There were no associations between coxa profunda and posterior wall sign or crossover sign in Cohort 2.

\section{Discussion}

Coxa profunda is often used to diagnose pincer FAI. Radiographically, coxa profunda is the finding of an acetabular fossa medial to the ilioischial line. However, the relative position of the acetabular fossa to the pelvis may not be indicative of acetabular coverage. We therefore determined the incidence of coxa profunda and evaluated associations between coxa profunda and other radiographic parameters of acetabular coverage commonly used to diagnose pincer FAI and acetabular dysplasia.

There were several limitations to our study. First, our symptomatic patients were represented by two patient cohorts with a predisposition to either acetabular over- or undercoverage rather than a single series of consecutive patients treated for hip pain at our institution. Second, our asymptomatic subjects were not fully representative of the general population but were a rather unique cohort of male collegiate football players previously reported to have a high prevalence of radiographic findings consistent with FAI [15]. Regardless of these possible limitations, these cohorts enabled us to fulfill our main purpose, which was to determine whether coxa profunda is found in both asymptomatic and symptomatic hips representing the spectrum of acetabular coverage. Third, clinicians familiar with the radiographic evaluation of FAI and dysplasia understand the classification of acetabular depth is highly dependent on the radiographic criteria of choice. Reported upper limits of cutoff values for normal LCE angle range from $35^{\circ}$ to $45^{\circ}[12,30]$. In our study, overcoverage was diagnosed by a LCE angle of greater than $40^{\circ}$, the midrange of reported LCE angles. The use of an alternative cutoff value would alter the reported incidence of hips with overcoverage but would not affect the finding that there was no difference in LCE angle between hips with and without coxa profunda. Fourth, the AP radiographs of Cohorts 2 and 3 were obtained standing, while the radiographs of Cohort 1 were obtained supine. However, both methods employed a standard radiographic technique to account for neutral pelvic tilt and rotation [33]. To our knowledge, there is currently no literature suggesting the measurement of acetabular coverage or the finding of radiographic coxa profunda would differ between supine and standing radiographs.

Our findings demonstrated an incidence of radiographic coxa profunda in the three cohorts of $34 \%$ to $56 \%$, values comparable to those previously reported for symptomatic populations using the same coxa profunda definition (Table 4). Philippon et al. [29] found the acetabulum touched the ilioischial line in $27 \%$ of hockey players treated with arthroscopy for FAI. Weir et al. [36] reported radiographic coxa profunda in 23 of 68 (34\%) hips in their study of patients with groin pain. Neuman et al. [21] found 25 of 45 (56\%) hips for FAI had coxa profunda. In another study by Beck et al. [3], 33 of 149 (22\%) hips treated by surgical dislocation for chondrolabral lesions had coxa profunda. These findings indicate the radiographic sign of the medial acetabular fossa touching the ilioischial line occurs in a substantial number of patients who are or may undergo hip preservation surgery. These patients also have wide variation in acetabular coverage using other coverage metrics $[2,3]$.

We found no relationship between radiographic coxa profunda and the LCE angle and acetabular index, measures routinely used to define the amount of acetabular coverage of the femoral head. While coxa profunda has been defined most commonly by the acetabular fossa projecting medial to the ilioischial line $[3,21,36]$, some studies have used anterior center edge (ACE) and LCE angles to classify hips as having coxa profunda, although there is no standard cutoff value $[13,14,17,22,30]$ (Table 4). For example, while Pollard et al. [30] suspected global overcoverage in hips with coxa profunda (fossa medial to ilioischial line), they also indicated other measurements of acetabular coverage were relevant (based on 95\% CI of normal hips without osteoarthritis), such as an LCE angle of greater than $38^{\circ}$ and/or an acetabular index of less than $-3.7^{\circ}$ (men) or less than $-4.9^{\circ}$ (women) or protrusio acetabuli. Using an LCE angle of greater than 
Table 4. Coxa profunda literature review

\begin{tabular}{|c|c|c|c|c|c|}
\hline Study & $\begin{array}{l}\text { Number } \\
\text { of hips }\end{array}$ & Sex & Symptomatic? & $\begin{array}{l}\text { Profunda } \\
\text { definition }\end{array}$ & $\begin{array}{l}\text { Profunda } \\
\text { incidence } \\
(\%)\end{array}$ \\
\hline Philippon et al. [29] & 28 & Male & Yes & IIL & 27 \\
\hline Neuman et al. [21] & 45 & Both & Yes & IIL & 25 \\
\hline Beck et al. [3] & 149 & Both & Yes & IIL & 22 \\
\hline Weir et al. [36] & 68 & Both & Yes & IIL & 34 \\
\hline \multicolumn{6}{|l|}{ Current study } \\
\hline Cohort 1 & 134 & Male & No & IIL & 34 \\
\hline Cohort 2 & 83 & Both & Yes & IIL & 58 \\
\hline Cohort 3 & 96 & Both & Yes & IIL & 56 \\
\hline Kang et al. [14] & 200 & Both & No & $\mathrm{CEA}>40^{\circ}$ & 16 \\
\hline Gosvig et al. [12] & 2664 & Male & Mixed & $\mathrm{CEA}>40^{\circ}$ & 15 \\
\hline Gosvig et al. [12] & 4576 & Female & Mixed & $\mathrm{CEA}>40^{\circ}$ & 19 \\
\hline \multicolumn{6}{|l|}{ Current study } \\
\hline Cohort 1 & 134 & Male & No & $\mathrm{CEA}>40^{\circ}$ & 6 \\
\hline Cohort 2 & 74 & Both & Yes & $\mathrm{CEA}>40^{\circ}$ & 0 \\
\hline Cohort 3 & 96 & Both & Yes & $\mathrm{CEA}>40^{\circ}$ & 22 \\
\hline
\end{tabular}

$\mathrm{IIL}=$ medial acetabular fossa touching or medial to ilioischial line; $\mathrm{CEA}=$ center edge angle.

$45^{\circ}, 15.2 \%$ of the 1332 men and $19.4 \%$ of the 2288 women from the Copenhagen Osteoarthritis Substudy had a deep acetabulum [12]. Kang et al. [14] examined CT images for findings associated with FAI in 100 patients with asymptomatic hips scanned for abdominal complaints or trauma and found a $16 \%$ incidence of coxa profunda $(77 \%$ bilateral) defined as an LCE angle of greater than $40^{\circ}$. For comparison, in our study, $6 \%$ of Cohort $1,0 \%$ of Cohort 2 , and $22 \%$ of Cohort 3 had an LCE angle of greater than $40^{\circ}$. Interestingly, coxa profunda occurred in 59\% (17 of 29) of hips with an LCE angle of greater than $40^{\circ}$ in our study. The lack of consensus in the literature regarding the LCE angle cutoff defining an overcovered acetabulum indicates defining a truly deep or overcovered socket based on a single measurement may be overly simplistic.

Similarly, we found coxa profunda did not consistently coexist with the crossover sign and posterior wall sign in the three cohorts. We did find a lower incidence of a positive posterior wall sign in hips with coxa profunda in the football player group (Cohort 1), although this was not consistently noted in the other cohorts. Additionally, there was a lower incidence of the crossover sign in hips with coxa profunda in Cohort 3, hips treated for FAI. One possible interpretation is that a deep-set acetabulum (coxa profunda) is associated with greater posterior acetabular coverage though not necessarily overcoverage of the acetabular roof.

In conclusion, coxa profunda, defined by the fossa medial to ilioischial line, was not consistently associated with acetabular overcoverage but rather coexisted with a spectrum of acetabular morphologies. As coxa profunda was a common radiographic finding in both symptomatic and asymptomatic hips, its contribution to the etiology of hip pain and arthrosis remains unknown. As only one hip had have protrusio acetabuli in our study, we cannot comment on associations between protrusio acetabuli and acetabular coverage. Nonetheless, acetabular coverage should be interpreted on a case-by-case basis in the context of focal and general acetabular coverage. We believe ACE and LCE angles and the position of the anterior and posterior acetabular walls relative to the center of the femoral head may be more suitable for identifying hips at risk for pincer impingement. Furthermore, we believe the classic radiographic definition of coxa profunda should not be used in the diagnosis of pincer FAI. Future investigations are needed to understand the range of normal acetabular morphology to improve the diagnostic criteria for pincer FAI.

Acknowledgments We acknowledge support from the University of Utah Department of Orthopaedics for assistance with funding, technical support, and facilities for the radiographs acquired for the football player cohort of this study. Additionally, we acknowledge Lee Phillips MD for help with radiographic reads, Andrew Anderson $\mathrm{PhD}$ with manuscript preparation, and Jill Erickson PA-C for maintaining the database used for the patient cohorts of this study.

\section{References}

1. Anderson LA, Peters CL, Park BB, Stoddard GJ, Erickson JA, Crim JR. Acetabular cartilage delamination in femoroacetabular 
impingement: risk factors and magnetic resonance imaging diagnosis. J Bone Joint Surg Am. 2009;91:305-313.

2. Bardakos NV, Villar RN. Predictors of progression of osteoarthritis in femoroacetabular impingement: a radiological study with a minimum of ten years follow-up. J Bone Joint Surg Br. 2009;91:162-169.

3. Beck M, Kalhor M, Leunig M, Ganz R. Hip morphology influences the pattern of damage to the acetabular cartilage: femoroacetabular impingement as a cause of early osteoarthritis of the hip. J Bone Joint Surg Br. 2005;87:1012-1018.

4. Beck M, Leunig M, Parvizi J, Boutier V, Wyss D, Ganz R. Anterior femoroacetabular impingement. Part II. Midterm results of surgical treatment. Clin Orthop Relat Res. 2004;418:67-73.

5. Clohisy JC, Carlisle JC, Beaule PE, Kim YJ, Trousdale RT, Sierra RJ, Leunig M, Schoenecker PL, Millis MB. A systematic approach to the plain radiographic evaluation of the young adult hip. J Bone Joint Surg Am. 2008;90(suppl 4):47-66.

6. Clohisy JC, Carlisle JC, Trousdale R, Kim YJ, Beaule PE, Morgan P, Steger-May K, Schoenecker PL, Millis M. Radiographic evaluation of the hip has limited reliability. Clin Orthop Relat Res. 2009;467:666-675.

7. Fadul DA, Carrino JA. Imaging of femoroacetabular impingement. J Bone Joint Surg Am. 2009;91(suppl 1):138-143.

8. Ganz R, Gill TJ, Gautier E, Ganz K, Krugel N, Berlemann U. Surgical dislocation of the adult hip: a technique with full access to the femoral head and acetabulum without the risk of avascular necrosis. J Bone Joint Surg Br. 2001;83:1119-1124.

9. Ganz R, Klaue K, Vinh TS, Mast JW. A new periacetabular osteotomy for the treatment of hip dysplasias: technique and preliminary results. Clin Orthop Relat Res. 1988;232:26-36.

10. Ganz R, Leunig M, Leunig-Ganz K, Harris WH. The etiology of osteoarthritis of the hip: an integrated mechanical concept. Clin Orthop Relat Res. 2008;466:264-272.

11. Giori NJ, Trousdale R. Acetabular retroversion is associated with osteoarthritis of the hip. Clin Orthop Relat Res. 2003;417: 263-269.

12. Gosvig KK, Jacobsen S, Sonne-Holm S, Palm H, Troelsen A. Prevalence of malformations of the hip joint and their relationship to sex, groin pain, and risk of osteoarthritis: a populationbased survey. J Bone Joint Surg Am. 2010;92:1162-1169.

13. Jacobsen S, Sonne-Holm S, Søballe K, Gebuhr P, Lund B. Radiographic case definitions and prevalence of osteoarthrosis of the hip: a survey of 4151 subjects in the Osteoarthritis Substudy of the Copenhagen City Heart Study. Acta Orthop Scand. 2004;75:713-720.

14. Kang AC, Gooding AJ, Coates MH, Goh TD, Armour P, Rietveld J. Computed tomography assessment of hip joints in asymptomatic individuals in relation to femoroacetabular impingement. Am J Sports Med. 2010;38:1160-1165.

15. Kapron AL, Anderson AE, Aoki SK, Phillips LG, Petron DJ, Toth R, Peters CL. Radiographic prevalence of femoracetabular impingement in collegiate football players. J Bone Joint Surg Am. 2011;93:e111(1-10).

16. Kubiak-Langer M, Tannast M, Murphy SB, Siebenrock KA, Langlotz F. Range of motion in anterior femoroacetabular impingement. Clin Orthop Relat Res. 2007;458:117-124.

17. Lequesne M, Malghem J, Dion E. The normal hip joint space: variations in width, shape, and architecture on 223 pelvic radiographs. Ann Rheum Dis. 2004;63:1145-1151.

18. Martin RL, Kelly BT, Philippon MJ. Evidence of validity for the hip outcome score. Arthroscopy. 2006;22:1304-1311.

19. Martin RL, Philippon MJ. Evidence of reliability and responsiveness for the hip outcome score. Arthroscopy. 2008;24: 676-682.
20. Mast JW, Brunner RL, Zebrack J. Recognizing acetabular version in the radiographic presentation of hip dysplasia. Clin Orthop Relat Res. 2004;418:48-53.

21. Neumann M, Cui Q, Siebenrock KA, Beck M. Impingement-free hip motion: the "normal" angle alpha after osteochondroplasty. Clin Orthop Relat Res. 2009;467:699-703.

22. Ochoa LM, Dawson L, Patzkowski JC, Hsu JR. Radiographic prevalence of femoroacetabular impingement in a young population with hip complaints is high. Clinical Orthop Relat Res. 2010;468:2710-2714.

23. Parvizi J, Leunig M, Ganz R. Femoroacetabular impingement. J Am Acad Orthop Surg. 2007;15:561-570.

24. Peters C, Erickson J, Hines J. Early results of the Bernese periacetabular osteotomy: the learning curve at an academic medical center. J Bone Joint Surg Am. 2006;88:1920-1926.

25. Peters CL, Erickson JA. Treatment of femoro-acetabular impingement with surgical dislocation and debridement in young adults. J Bone Joint Surg Am. 2006;88:1735-1741.

26. Peters CL, Schabel K, Anderson L, Erickson J. Open treatment of femoroacetabular impingement is associated with clinical improvement and low complication rate at short-term followup. Clin Orthop Relat Res. 2010;468:504-510.

27. Philippon M, Schenker M, Briggs K, Kuppersmith D. Femoroacetabular impingement in 45 professional athletes: associated pathologies and return to sport following arthroscopic decompression. Knee Surg Sports Traumatol Arthrosc. 2007;15:908-914.

28. Philippon MJ, Stubbs AJ, Schenker ML, Maxwell RB, Ganz R, Leunig M. Arthroscopic management of femoroacetabular impingement: osteoplasty technique and literature review. Am J Sports Med. 2007;35:1571-1580.

29. Philippon MJ, Weiss DR, Kuppersmith DA, Briggs KK, Hay CJ. Arthroscopic labral repair and treatment of femoroacetabular impingement in professional hockey players. Am J Sports Med. 2010;38:99-104.

30. Pollard TC, Villar RN, Norton MR, Fern ED, Williams MR, Murray DW, Carr AJ. Genetic influences in the aetiology of femoroacetabular impingement: a sibling study. J Bone Joint Surg Br. 2010;92:209-216.

31. Reynolds D, Lucas J, Klaue K. Retroversion of the acetabulum: a cause of hip pain. J Bone Joint Surg Br. 1999;81:281-288.

32. Ruelle M, Dubois JL. [Protrusive malformation and its arthrotic complication. II. The arthrotic complication] [in French]. Rev Rhum Mal Osteoartic. 1962;29:646-654.

33. Siebenrock K, Kalbermatten DF, Ganz R. Effect of pelvic tilt on acetabular retroversion: a study of pelves from cadavers. Clin Orthop Relat Res. 2003;407:241-248.

34. Tannast M, Siebenrock KA, Anderson SE. Femoroacetabular impingement: radiographic diagnosis-what the radiologist should know. AJR Am J Roentgenol. 2007;188:1540-1552.

35. Tannast M, Zheng G, Anderegg C, Burckhardt K, Langlotz F, Ganz R, Siebenrock KA. Tilt and rotation correction of acetabular version on pelvic radiographs. Clin Orthop Relat Res. 2005;438:182-190.

36. Weir A, de Vos RJ, Moen M, Holmich P, Tol JL. Prevalence of radiological signs of femoroacetabular impingement in patients presenting with long-standing adductor-related groin pain. $\mathrm{Br} \mathrm{J}$ Sports Med. 2011;45:6-9.

37. Werner CM, Copeland CE, Ruckstuhl T, Stromberg J, Turen $\mathrm{CH}$, Kalberer F, Zingg PO. Radiographic markers of acetabular retroversion: correlation of the cross-over sign, ischial spine sign and posterior wall sign. Acta Orthop Belg. 2010;76:166-173.

38. Zebala LP, Schoenecker P, Clohisy J. Anterior femoroacetabular impingement: a diverse disease with evolving treatment options. Iowa Orthop J. 2007;27:71-81. 